\title{
Augmenting the Heat Sink for Better Heat Dissipation
}

\author{
Mohammed H. S. Al Ashry \\ Department of Computer Science, the Community College, College of Sciences and Humanities, Shaqra \\ University, Shaqra, Saudi Arabia \\ Email: mashry@su.edu.sa
}

Received 31 January 2015; accepted 14 February 2015; published 15 February 2015

Copyright (C) 2015 by author and Scientific Research Publishing Inc.

This work is licensed under the Creative Commons Attribution International License (CC BY).

http://creativecommons.org/licenses/by/4.0/

(c) (i) Open Access

\begin{abstract}
Heat sinks were invented to absorb heat from an electronic circuit conduct, and then to dissipate or radiate this heat to the surrounding supposedly, ventilated space, at a rate equal to or faster than that of its buildup. Ventilation was not initially recognized as an essential factor to thermal dispersion. However, as electronic circuit-boards continued to heat up, circuit failure became a problem, forcing the inclusion of miniaturized high speed fans. Later, heat sinks with fins and quiet fans were incorporated in most manufactured circuits. Now heat sinks come in the form of a fan with fans made to function as fins to disperse heat. Heat sinks absorb and radiate excess heat from circuit-boards in order to prolong the circuit's life span. The higher the thermal conductivity of the material used the more efficient and effective the heat sink is. This paper is an attempt to theoretically design a heat sink with a temperature gradient lower than that of the circuit board's excess heat.
\end{abstract}

\section{Keywords}

Convective Heat Transfer: Heat Absorbed by the Natural Air Flow Surrounding Hot Objects, Forced Convective Heat Transfer: Absorption of Heat Using Forced Air Flow, Conductivity: Is the Ability of a System to Exchange or Transfer Temperature within a Body or Material through the Movement of Electrons, Material That Does Not Conduct Heat Is Considered a Nonconductor

\section{Introduction}

The way that the heat sink is attached to the circuit-board is a major contributor to the efficiency of its heat conductive-absorptivity. The heat-sink's ability to dissipate and radiate heat at a rate faster than or equal to its absorbency pace is critical to protect, maintain and extend the lifespan of the circuit. The type of material used for 
the sink and the juncture is crucial in terms of thermal conductivity, heat capacity, emissivity, resistivity and absorptivity. Heat is absorbed or transferred from a material at a higher temperature to a material at a lower temperature. The greater the temperature disparity among the materials, in the direction from the board to the heat sink on to the surrounding, the faster the pace at which heat is either absorbed or transferred. Heat moves among metals through the diffusion of electrons among atoms until a heat balance between the two contacting materials is established [1]. This transfer of heat is actually a transfer of electrons energy from a more energetic (hot) substance to one that is less energetic (colder) [2]; this analogy emphasizes contact between the two substances. It is important that the separate substances used are joined together using some form of amalgamation for a complete fusion at the entire circuit-board to heat-sink contact areas. Fusing the substances leads to better transfusion of electrons through the substances. To eliminate the possibility of overheating of either the sink or the circuit board ducted cooling fans scheme is introduced where fans/blowers are positioned in a way that is conducive to increased fluctuating air flow velocity around the heat sink, resulting from the revolving angled fins of the fans and the positioning of the alternating dual fans system. Although the alternating function of the two fans (Figure 1) does not change the eventual constant and consisting air flow velocity, the alternating effects do lower the pressure at the tightening end of the duct. This system allows for a decrease in heat sink's fins-spacing and its boundary layer thickness, and its fluctuating temperature gradient, and leads to an increase in convection heat-transfer. This leads to a higher rate of cooling of the heat-sink fins and a faster pace of cooling of the circuit board. This scheme, to a certain extent, allows for a reasonably greater height and length in heat sink's fins.

\section{Analysis}

Figure 2 provides us with the relationship between heat and heat transfer and its equal in electrical circuits and functions. Heat movement within metals is similar to movement of amps in an electric circuit. Temperature functions in the same way as voltage and thermal resistivity functions like that of electric resistance. So that

$$
i=\left(V_{1}-V_{2}\right) / R \equiv Q=\left(T_{2}-T_{1}\right) / \varnothing
$$

Equation (1) displays the heat and ampere equations' parallelism they are to a certain extent equivalent in form and behavior.

The heat sink design must emphasize a large surface area in order to utilize the forced convection heat transfer induced by the fan-made airflow. Figure 3 displays an approximate view of the heat sink within the exit side of the duct. It is obvious that the heat sink's back view almost fits into the square shape of the duct vertical to the direction of the flow. However it is a little shorter in the direction of the flow.

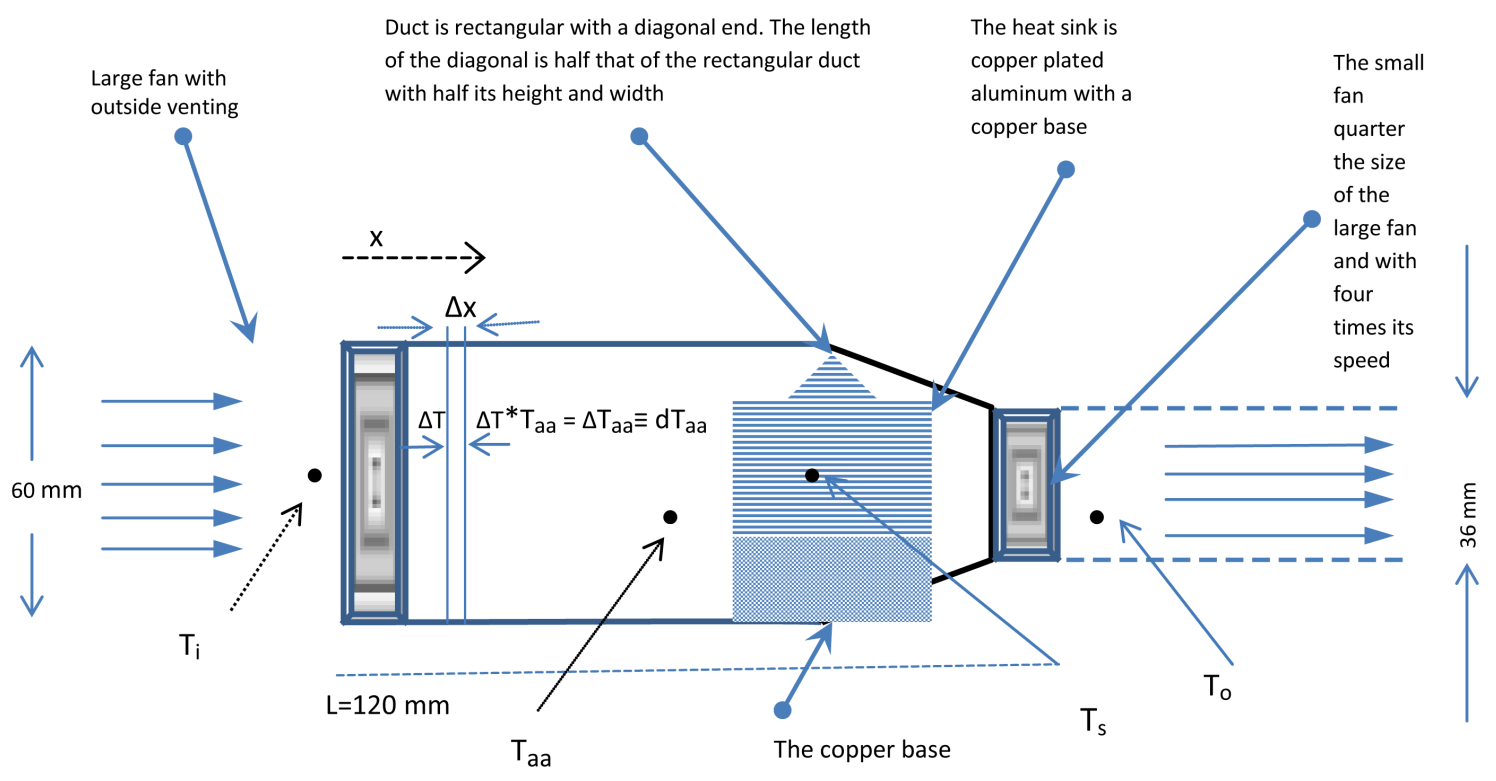

Figure 1. The ducted fan and heat sink. 


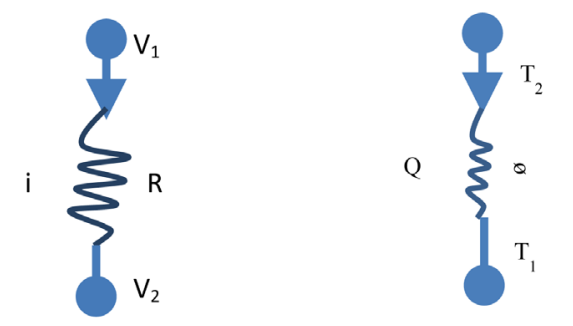

Figure 2. Electrical and thermal circuit analysis of the similarity between heat and electricity [3].

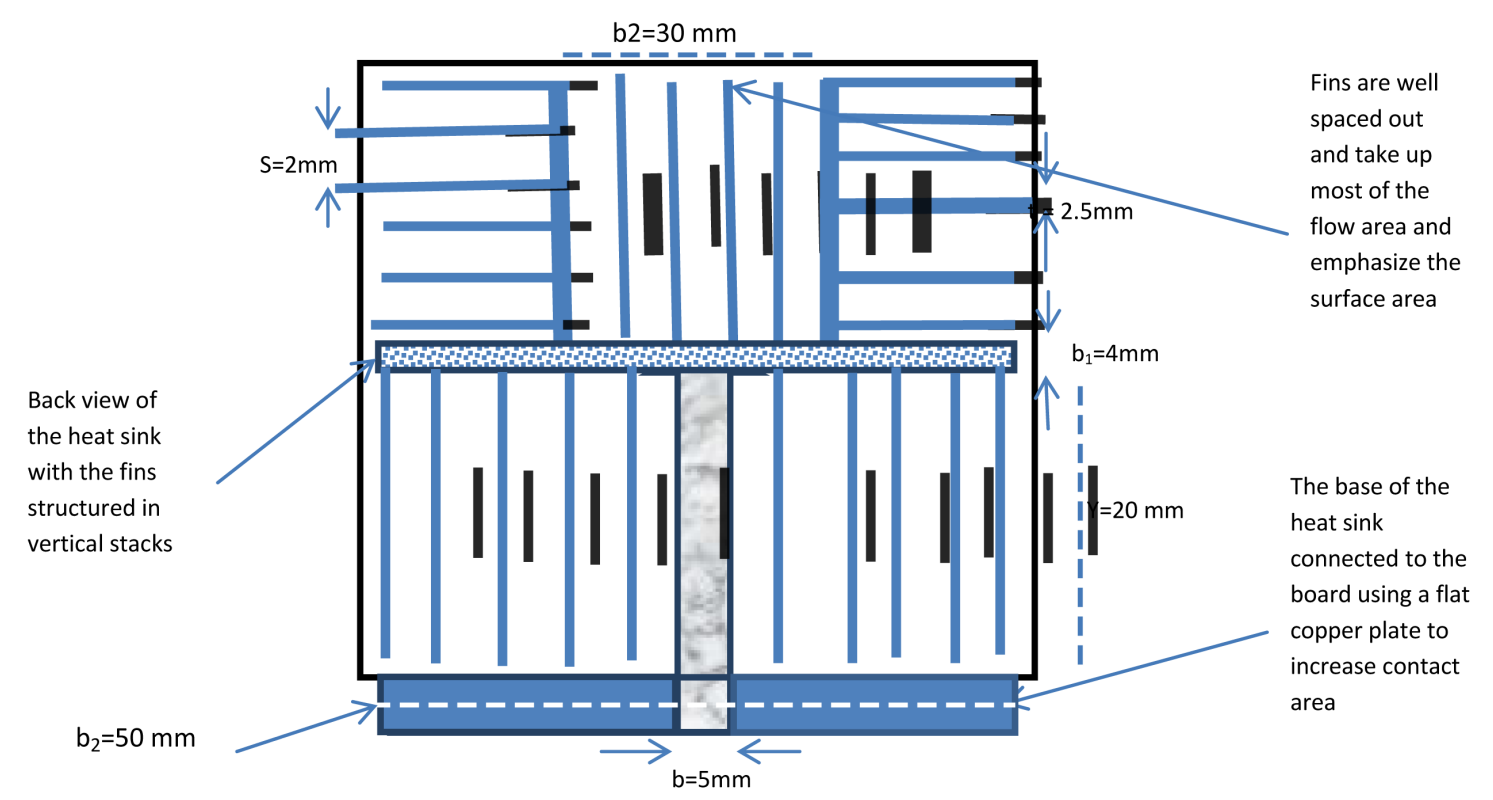

Figure 3. Back view of the heat sink.

Figure 4 displays a view of the copper plates connecting the base of the sink to the circuit board. The views focus on the plates from top and bottom of the board and its relationship to the base of heat sink. It should be noted that the diagrams are not exact representations of an actual sink.

The heat sink, the base and the juncture are made up of copper. The base and the heat sink are heat-based welded so the heat resistivity between the two parts can be considered equal to the thermal resistivity of copper. The base is attached to the juncture by rolling the plates around the side of the base and using high pressure guns to attach them. The bottom of the base is attached to the plates using high pressure, and beryllium oxide is used to fill the gaps for lower heat resistance and higher thermal conductivity. The thermal conductivity of beryllium oxide ( $>200)$ is greater than that of aluminum. This will make it possible for us to neglect under certain circumstances the existence of a ceramic-grease-based gap-filler.

The fans will provide the heat sink with continuous air flow that will lower the temperature of the heat sink and facilitate the transfer and dissipation of heat through the ducted stream. The two fans provide us with many advantages, faster air streaming through the heat sink fins' spacing due to the vacuuming effect created by the second fan and continuous air flow in case one of the two fans went out; assuming, of course, a fan functional sensor is available and working.

Assuming the fans are timed to alternate that will create the wind tunnel effects of gusting which increases the affected fins' surface area. The two fans, due to the difference in size will have a different rotational speed and timely alternating flow as follows [4]:

The air volume flux can be calculated using the area of the fan's opening, and the fans air speed.

$$
\dot{V}=V_{a} \mathrm{~d} A_{s}=V_{a}(w) \mathrm{d} L
$$

where $w$ is the width of the duct, and $L$ is the length) 
The following views, top to bottom- left to right, are not exact representations of the real thing, the top view (\#1) shows the location of the juncture plate view (\#2) is a horizontal view of the plates being machine-pressed and fastened into the board. View (\#3) shows the plate from the top fused to the board, view (\#4) shows the sink welded using high heat-based soldering on top of the fused copper plates for a perfect electrically-based contact with the sink on top. The base is made transparent for obvious purposes.

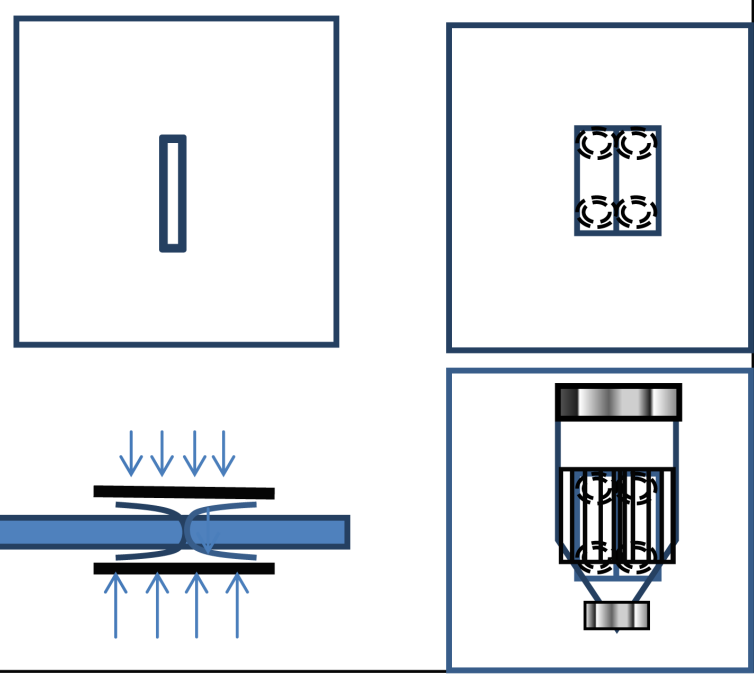

Figure 4. Views of the circuit board juncture and sink.

To calculate the gusting of the air movement we have

$$
\mathrm{d}(\dot{V}) / \mathrm{d} t=A_{s} \mathrm{~d} V_{a} / \mathrm{d} t
$$

The area of the smaller fan is used to measure and gauge its rotational speed in order to attain adequate energy to produce the necessary speed.

The alternation can be timed using a switching control system [5]. The velocity of the air flow will be mostly constant with the exception of the time in which one fan shuts down and the other starts. There are a number of objectives behind this fan design as an option:

1) The increase of air velocity increases the "forced" convective heat transfer;

2) The air speed increases the areas reached by the air flow inside the spacing of the sink's fins, which in turn increases the functionality of the heat sink, and decreases thermal resistance;

3) This technique supports an increase in the duct's air pressure over the surface of the sink's fins; although the design where the duct's outlet narrows gradually towards the duct's opening creating a bottleneck effect and increasing the pressure on the sink's leading edge and inner surface, especially the deep ends of the fins' spacing on both sides of the sink;

4) A noticeable pressure drop will be noticed at the outlet;

5) The alternating fans create an air flow's gusting effect that acts as an additional coolant to the sink's heated surface;

6) This method extends both the life of the computer, its major components including the fans;

7) The system will increase the surface area by allowing for more fins and thinner spacing between the fins.

\section{The Approach}

The thermal resistance can be obtained using Equation (1)

$$
\varnothing=\left(T_{2}-T_{1}\right) / Q=\Delta T_{21} / Q
$$

Since both the radiation and forced convection heat transfer are active for the sink in our ducted heat sink scheme then starting with forced convective heat transfer we have the following:

Heat transferred out of the sink is measured on the basis of the temperature difference between the heat sinkfins' surfaces and the surrounding:

$$
Q_{t}=h_{c} A_{s}\left(T_{s}-T_{a a}\right)
$$

But the convective heat transferred to the surrounding seeps through the sink's bases and fins where their positioning and attributes, length, height, angles, thickness and spacing, have a lot to do with the heat exchange. Figure 1 and Figure 3 are essential to the rest of this paper. The formula for the convective heat exchange is 


$$
Q=\dot{\eta} h_{c} A_{s}\left(T_{0}-T_{i}\right)
$$

where $\dot{\eta}$ is the fins efficiency coefficient $h_{c}$, is the heat transfer coefficient and $A_{s}$ is the fins surface area, and the temperature difference between the outlet and inlet of the duct $\left(T_{0}-T_{i}\right)$

But since $\varnothing=\left(T_{0}-T_{i}\right) / Q$ and using Equation (6) we have

$$
\varnothing=\left(T_{s}-T_{a a}\right) / Q=1 /\left(\dot{\eta} h_{c} A_{s}\right)
$$

We know that $\Delta T_{\text {saa }}$ is proportional to the sink's temperature, however, thermal resistance is dependent to a certain extent on the convective air flow velocity about the heat sink's fins.

However, we know that the quantity of heat absorbed by the air is:

$$
Q_{c}=\dot{\eta} \dot{m} C_{p}\left(T_{0}-T_{i}\right)
$$

But since the thermal resistivity is dependent on the fins' surface area and type of material we have $\dot{\eta}$, the fins efficiency, which can be calculated by going back to heat coefficient formulations:

$$
\dot{\eta}=Q /\left(h_{c} A_{s} \Delta T_{0 i}\right)=Q /\left(\dot{m} C_{p} \Delta T_{21}\right)
$$

We know that heat capacitance

$$
C_{p}=\Delta Q / \Delta T_{0 i}
$$

and air mass flux rate

$$
\dot{m}=\rho \dot{\mathrm{V}}=\rho v \mathrm{~d} A_{s}=\rho \mathrm{d} V / \mathrm{d} t
$$

with density $\rho$, and flow velocity $v$ and change in volume $\mathrm{d} V$; Using parallel and series heat transfer coefficients for the fins structure, for parallel fins

$$
h_{f p}=h_{1}+h_{2}+h_{3}+\cdots
$$

and for fins in series

$$
h_{f p}=[1 / h+1 / h+1 / h+\cdots]
$$

Respectively we have

$$
\dot{\eta}=\tanh (m l) /(m l)
$$

where

$$
m=\left(2 h_{\text {fin }} / k t\right)^{1 / 2}
$$

Then

$$
\dot{\eta}=\tanh \left(\left(2 h_{f i n} / k t\right)^{1 / 2} l\right) /\left(\left(2 h_{f i n} / k t\right)^{1 / 2} l\right)
$$

where $l=$ the fin's length, $k=$ thermal conductivity, and $t=$ fin thickness.

The second channel of emitting heat through the heat sink is the radiation of heat through the fins which is influenced by the material used, emissivity and the energy radiated by a surface in relationship to a black body. where

$$
Q_{r}=\varepsilon \sigma A_{s}\left(T_{s}^{4}-T_{a a}^{4}\right)
$$

The heat transfer coefficient of radiation $h_{r}$ is

$$
h_{r}=\varepsilon \sigma\left(T_{s}+T_{a a}\right)\left(T_{s}^{2}-T_{a a}^{2}\right)
$$

Where $\varepsilon$ is the emissivity and $\sigma$ is the Stefan Botlzmann constant, which is based on atomic radiation of elements and is measured in vacuum at the speed of light [6].

The Boltzmann constant $=5.67 \times 10^{-8}$ watt $/ \mathrm{m}^{2} \mathrm{~K}^{4}$, emissivity of copper $=0.04$ (dimensionless).

The thermal resistance in the radiation case is inversely proportional to both the surface area $A_{s}$ and the 
radiation heat transfer coefficient $h_{r}$.

Now it is a good idea to go back to the thermal resistance of the heat between the circuit and the heat-sink's surrounding where total thermal resistance between the sink-circuit board-juncture and the air surrounding the heat sink

$$
\varnothing_{j a}=\varnothing_{j c}+\varnothing_{c s}+\varnothing_{s a}
$$

but

$$
\varnothing_{s a}=\varnothing_{j a}-\left(\varnothing_{j c}+\varnothing_{c s}\right)
$$

Equation (18) shows the need for a high dissipative outlet to prevent over heating however the unknown in this case is the added element that is not made obvious by Equation (15), the forced-convective heat transfer dispersing heat through cooling of the fins surface by the high, double-fanned air flow velocity.

The total rate of convective and radiative heat transfer for the entire heat sink fins is

$$
Q_{t}=Q_{c}+Q_{r}=h_{c} A_{s}\left(T_{s}-T_{a a}\right)
$$

Assuming we have $n_{c f}$ fins (total $\#$ of corner fins) $=12$ and 2 millimeter $(\mathrm{mm})$ of spacing between fins, over a cubic volume of $(50 * 40 * 50) \mathrm{mm}^{3}$, as in Figure 3, with two parallel lanes of lines of fins on top of and below the middle base all aligned in the direction of the flow and with equal fins' thicknesses of approximately $2.5 \mathrm{~mm}$ and spacing of $2 \mathrm{~mm}$, we have ten fins facing down in the bottom half, $20 \mathrm{~mm}$ in height, and two lines of six fins in the top right and left corners, $12 \mathrm{~mm}$ in height and four fins in the middle top of the heat sink, $25 \mathrm{~mm}$ in height. We have a $4 \mathrm{~mm}$ middle horizontal base and a $5 \mathrm{~mm}$ vertical base. The two vertical bases holding the right and left top corners' fins are $3 \mathrm{~mm}$ in thickness. The duct is $120 \mathrm{~mm}$ long has a wide area with a square cross section $(60 * 60)$ $\mathrm{mm}^{2}$ as its inlet, and is $60 \mathrm{~mm}$ long, the rest of the duct $60 \mathrm{~mm}$ long, narrowing down at a (2/5) gradient in the direction of the flow; so for each $5 \mathrm{~mm}$ length the duct is narrower by $2 \mathrm{~mm}$, with a $(36 * 36)$ cross section outlet. The convective heat transfer through the duct is

$$
\begin{aligned}
Q_{c}= & {\left[\left(n_{c f}+1\right) *\left\{\left[2\left(b_{2}-2 b\right)+\left(b_{1}+s\right)\right] *(b-10)\right\}+\left(n_{c f}-1\right)\{[2 y+(t+s)] *(b-10)\}\right.} \\
& \left.+\left(n_{c f}-8\right)\left\{2\left(b-\left(y+b_{1}\right)\right)+(t+s)\right\} *(b-10)\right] \dot{\eta} h_{c}\left(T_{0}-T_{i}\right), \\
Q_{c}= & {\left[\left(n_{c f}+4\right) *\left\{(t+s)+\left(2 b_{1}\right)+2\left(b_{1}-0.001\right)\right\} *(b-10)+2 y(b-10)\right] \varepsilon \sigma\left(T_{s}^{4}-T_{a a}^{4}\right) }
\end{aligned}
$$

where $\quad h_{\text {fin }}=k / t$ and $\dot{\eta}=0.092$.

$$
\varepsilon \sigma=(0.04) * 5.67 \times 10^{-8}=3.744 \times 10^{-8}
$$

Now consider Equation (20) again where

$$
Q_{t}=h_{c} A_{s}\left(T_{s}-T_{a a}\right)=\dot{\eta} \dot{m} C_{p}\left(T_{0}-T_{i}\right)+\varepsilon \sigma A_{s}\left(T_{s}^{4}-T_{a a}^{4}\right)
$$

In Equation (23) however, radiation is ignored and Table 1 provides us with reasonable rationale to do so.

This means that only a small percentage of the heat transferred from the surface of the sink is done through radiation, and considering the radiation heat Equation (16) we can tell that $Q_{r}$ is dependent on the radiating area exposed to the surrounding and the temperature difference between the sink's dissipating surface and the ambient air. Based on the above mentioned assumptions, we can rewrite Equation (23)

\section{Table 1. Radiation deficiencies in finned heat sinks.}

Radiation heat transfer is almost negligible in comparison to the convective heat transfer for the following reasons

1) Radiation within the fins spacing goes into other fins.

2) Only radiation from the tips of the fins' surfaces reaches surrounding bodies.

3) Radiation is subject to exposed surface material and its emissivity.

4) Forced convective heat-transfer amplifies convection of the sink's heat and diminishes the importance of the radiation heat transfer in scope and magnitude. 


$$
Q_{t}=h_{c} A_{s}\left(T_{s}-\breve{T}_{a a}\right)=\dot{\eta} \dot{m} C_{p}\left(T_{0}-T_{i}\right)
$$

Now the ambient temperature $\breve{T}_{a a}$ is really the temperature of the vicinity of the sink, not the Inlet temperature, as some may assume. In order to determine the quality of a heat sink the heat transfer coefficient, conductivity, thermal resistance and or pressure drop in the duct around the sink needed to be ascertained and verified. There are a number of ways to do that and manipulating heat formulas is one of them. Equation (24) has the total heat transfer equal to the forced convective heat transfer. Radiation heat transfer is eliminated to simplify solving and manipulating the equation and Table 1, provides ample justifications to do just that.

$$
\breve{T}_{a a}=T_{s}-\dot{\eta} \dot{m} C_{p}\left(T_{0}-T_{i}\right) /\left(h_{c} A_{s}\right)
$$

If we set Equation (25) equal to zero, and differentiating over the distance before and after the sink, and assuming constant air speed (velocity), which means that the mass flow rate $\dot{m}$, is also constant, also assuming constant heat transfer coefficient $h_{c}$, however, the air flow speed is also assumed to be a uniform average of the inlet and outlet velocities across the duct, a constant. Now we can build the following integral formula

$$
h_{c} A_{s}\left(T_{s}-T_{a a}\right)-\dot{\eta} \dot{m} C_{p}\left(T_{0}-T_{i}\right)=0
$$

by dividing both sides by the total heat transfer we get

$$
1-\left(\dot{\eta} \dot{m} C_{p} / h_{c} A_{s}\right)\left(T_{0}-T_{i}\right) /\left(T_{s}-T_{a a}\right)=0
$$

$A_{s}=F_{i} \Delta x$ where $F_{i}$ is the wetted perimeter of the heat sink covering the entire surface of the sink's fins. $\Delta x$, is the discrete distance from the leading edge of the sink, where $x$ becomes the length of the duct $L$ at the outlet fan. The assumption that the inlet-outlet average temperature is uniform and constant is based on a uniform balance between air velocity within the sink's fins and the convection of heat from within the sink's wetted perimeter throughout the sink, this allows us to integrate the uniform duct's ambient temperature over the distance surrounding the sink in the direction of air flow. $T_{a a}$ is a constant average temperature across the duct so using Figure 2 and Equation (27) we have:

$$
T_{i}=\int_{T_{i}=T(x)}^{T_{0}=T(x+\Delta x)}\left(T_{a a}\right) \mathrm{d} t
$$

where

$$
\left(T_{a a}\right) *\left(T_{(x+\Delta x)}-T_{(x)}\right)=T_{a a} * T_{(\Delta x)}=\Delta T_{a a} \equiv \mathrm{d} T_{a a}
$$

and by integrating over the duct's length over the perimeter of the sink we have

$$
-\left(\dot{\eta} \dot{m} C_{p} / h_{c} F_{i}\right) \int_{T_{i}=T(x)}^{T_{0}=T(x+\Delta x)}\left(T_{a a}\right) \mathrm{d} t /\left(T_{s}-T_{a a}\right) \Delta x
$$

where, in this case $T_{a a}=\left(T_{0}+T_{i}\right)$ average across duct

Equation (26) becomes

$$
\begin{gathered}
1-\left(\dot{\eta} \dot{m} C_{p} / h_{c} F_{i}\right) \mathrm{d} T_{a a} /\left(T_{s}-T_{a a}\right) \Delta x=0 \\
1-\left(\dot{\eta} \dot{m} C_{p} / h_{c} F_{i} \Delta x\right) \mathrm{d} T_{a a} /\left(T_{s}-T_{a a}\right)=0 \\
\left(h_{c} F_{i}\right) \mathrm{d} x=\dot{\eta} \dot{m} C_{p} \mathrm{~d} T_{a a} /\left(T_{s}-T_{a a}\right)
\end{gathered}
$$

Using the integration process

We have $\left(T_{s}-T_{a a}\right)=u$, and $-\mathrm{d} T_{a a}=\mathrm{d} u$ we get

$$
\begin{gathered}
\left(h_{c} F_{i}\right) \int_{0}^{x} \mathrm{~d} x=\dot{\eta} \dot{m} C_{p}\left\{\int_{T_{i}}^{T_{s}} \int_{T_{a a}}^{T_{s}} \mathrm{~d} u / u\right\} \\
h_{c} F_{i} x=\dot{\eta} \dot{m} C_{p}\left\{1 /\left(T_{s}-T_{a a}\right)-1 /\left(T_{s}-T_{i}\right)\right\} \mathrm{d} u \\
-\left(h_{c} F_{i} x\right) /\left(\dot{\eta} \dot{m} C_{p}\right)=\left\{\ln \left(\left(T_{s}-T_{a a}\right) /\left(T_{s}-T_{a a}\right)\right)\right\}
\end{gathered}
$$




$$
\left\{\ln \left(\left(T_{s}-T_{a a}\right) /\left(T_{s}-T_{a a}\right)\right)\right\}=-\left(h_{c} F_{i} x\right) /\left(\dot{\eta} \dot{m} C_{p}\right)
$$

Using $\log$ rules

$$
\left(T_{s}-T_{a a}\right)=\left(T_{s}-T_{i}\right) \mathrm{e}^{\left(h_{c} F_{i} x\right) /\left(\eta \dot{m} C_{p}\right)}
$$

Now we can get the average ambient temperature, which we already assumed to be equivalent to the average temperature across the duct in air flow direction:

$$
T_{a a}=T_{s}-\left(T_{s}-T_{i}\right) \mathrm{e}^{\left(h_{c} F_{i} x\right) /\left(\eta \dot{m} C_{p}\right)}
$$

At $x=L$ we have $T_{a a}=T_{0}$

$$
T_{0}=T_{s}-\left(T_{s}-T_{i}\right) e^{\left(h_{c} F_{i} L\right) /\left(\eta \dot{m} C_{p}\right)}
$$

To get the average ambient temperature $\breve{T}_{a a}$

We use Equation (39) in Equation (25) to get

$$
\begin{gathered}
\breve{T}_{a a}=\dot{\eta} \dot{m} C_{p}\left(T_{s}-\left(T_{s}-T_{i}\right) \mathrm{e}^{\left(h_{c} F_{i} L\right) /\left(\dot{\eta} \dot{m} C_{p}\right)}-T_{i}\right) /\left(h_{c} A_{s}\right)+T_{s} \\
\breve{T}_{a a}=T_{s}-\left(\dot{\eta} \dot{m} C_{p} / h_{c} A_{s}\right)\left(T_{s}-T_{i}\right)\left(1-\mathrm{e}^{\left(h_{c} F_{i} L\right) /\left(\dot{\eta} \dot{m} C_{p}\right)}\right)
\end{gathered}
$$

Now we can get the total heat transfer by using Equation (41) in Equation (24) to get

$$
Q_{t}=T_{s}-\left(\dot{\eta} \dot{m} C_{p}\right)\left(T_{s}-T_{i}\right)\left(1-\mathrm{e}^{\left(h_{c} F_{i} L\right) /\left(\dot{\eta} \dot{m} C_{p}\right)}\right)
$$

Now it is obvious that the difference in temperature between the sink temperature and the inlet can be used to derive the total juncture to ambient thermal resistance. And it can also be assumed that the difference between the sink's temperature and the outlet temperature can be used to derive the radiative heat transfer. The difference between the two thermal resistances is the forced convective thermal resistance.

$$
\begin{gathered}
\varnothing_{j a}=\left(T_{s}-T_{i}\right) / Q_{t}=\left(\dot{\eta} \dot{m} C_{p}\right)\left(1-\mathrm{e}^{\left(h_{c} F_{i} L\right) /\left(\dot{\eta} \dot{m} C_{p}\right)}\right) \\
\left(T_{s}-T_{0}\right)=\left(T_{s}-T_{i}\right) \mathrm{e}^{\left(h_{c} F_{i} L\right) /\left(\dot{\eta} \dot{m} C_{p}\right)}
\end{gathered}
$$

The ratio of radiative to total heat transfer is

$$
\left(T_{s}-T_{0}\right) /\left(T_{s}-T_{i}\right)=Q_{r} / Q_{t}
$$

And so

$$
Q_{r}=\frac{T_{s}-T_{0}}{\left(T_{s}-T_{i}\right) * Q_{t}}
$$

Based, of course, on the material's high thermal conductivity, however, its dissipative-dispersive and radiative attributes are due not only to its above mentioned heat transfer qualities, but also due to the forced-convective heat transfer feature [7]. Experiments [8] have proven that increasing convective air flow velocity by 70 percent, decreases conductive resistance by $75-80$ percent on the surface of the heat sink. This feature is very compelling and puts emphasis on the utilization of forced convective air flow.

\section{Conclusion}

The heat sinks are neither expensive nor difficult to design or manufacture. The major aspect in heat sinks' design is sampling of the parts in central areas within the circuit board for better easier access to the heat source for better absorption. Central areas within circuit boards are not easily accessible for heat sinks' fusing and sampling. The central circuit-board locations' inaccessibility is a bit challenging to electronic designers when attempting to link the separate parts together for better and faster bussing and data communication. The right heat sink in the right 
spot within a circuit board facilitates heat conductivity-absorption and dissipation, and extends the life span of the board and its major components. The dual fan design keeps a constant air flow, infiltrates the heat sink's narrow fins' spacing, increases surface area, leads to higher convective heat transfer, and reduces pressure at the outlet. The design is made to force the air into the inner regions of the fins' spacing, and the outlet fan alleviates the pressure build up-forward to the sink. I recommend this system for high heat circuit-boards.

\section{References}

[1] http://WATLOW.COM

[2] http://encyclopedia2.thefreedictionary.com/thermodynamics+processes

[3] Lee, S. How to Select a Heat Sink. Advanced Thermal Engineering, Aavid Thermal Technologies, Inc., Laconia.

[4] Hamburgen, W.R. (1986) Optimal Finned Heat Sinks. Digital Equipment Corporation, Western Research Laboratory, Palo Alto.

[5] Sridhar, R. (2011) Discretization of Convection-Diffusion Type Equation. 10th Indo-German Winter Academy, Indian Institute of Technology, Madras.

[6] ICT International Pty Ltd. Theory of Emissivity. DocRef: Ver 1.1, Armidal NSW 250, Australia. www.ictinternational.com.au

[7] Qu, W. and Mudawar, I. (2002) Analysis of Three Dimensional Heat Transfer in Micro-Channel Heat Sinks. School of Mechanical Engineering, Purdue University, West Lafayette.

[8] Haskel, M.D. Thermal Resistance Comparison of Graphite Foam, Aluminum, and Copper Heat Sinks. http://www.electronics-cooling.com/2006/02/thermal-resistance-comparison-of-graphite-foam-aluminum-and-copper-h eat-sinks/ 
Scientific Research Publishing (SCIRP) is one of the largest Open Access journal publishers. It is currently publishing more than 200 open access, online, peer-reviewed journals covering a wide range of academic disciplines. SCIRP serves the worldwide academic communities and contributes to the progress and application of science with its publication.

Other selected journals from SCIRP are listed as below. Submit your manuscript to us via either submit@scirp.org or Online Submission Portal.
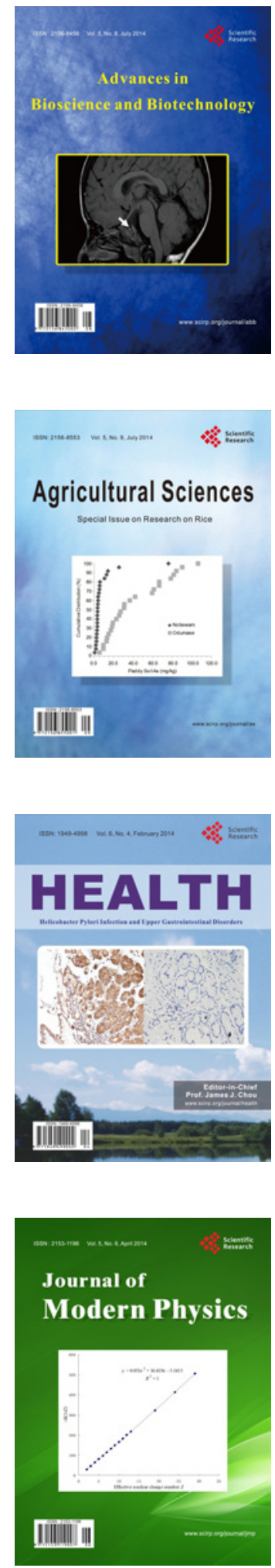
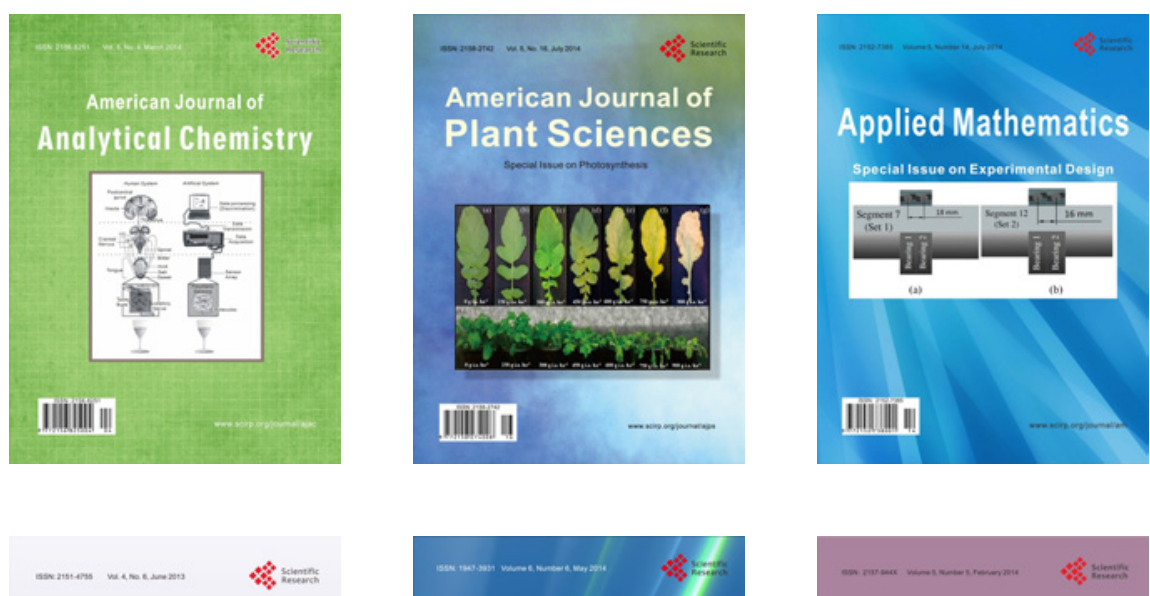

Creative Education
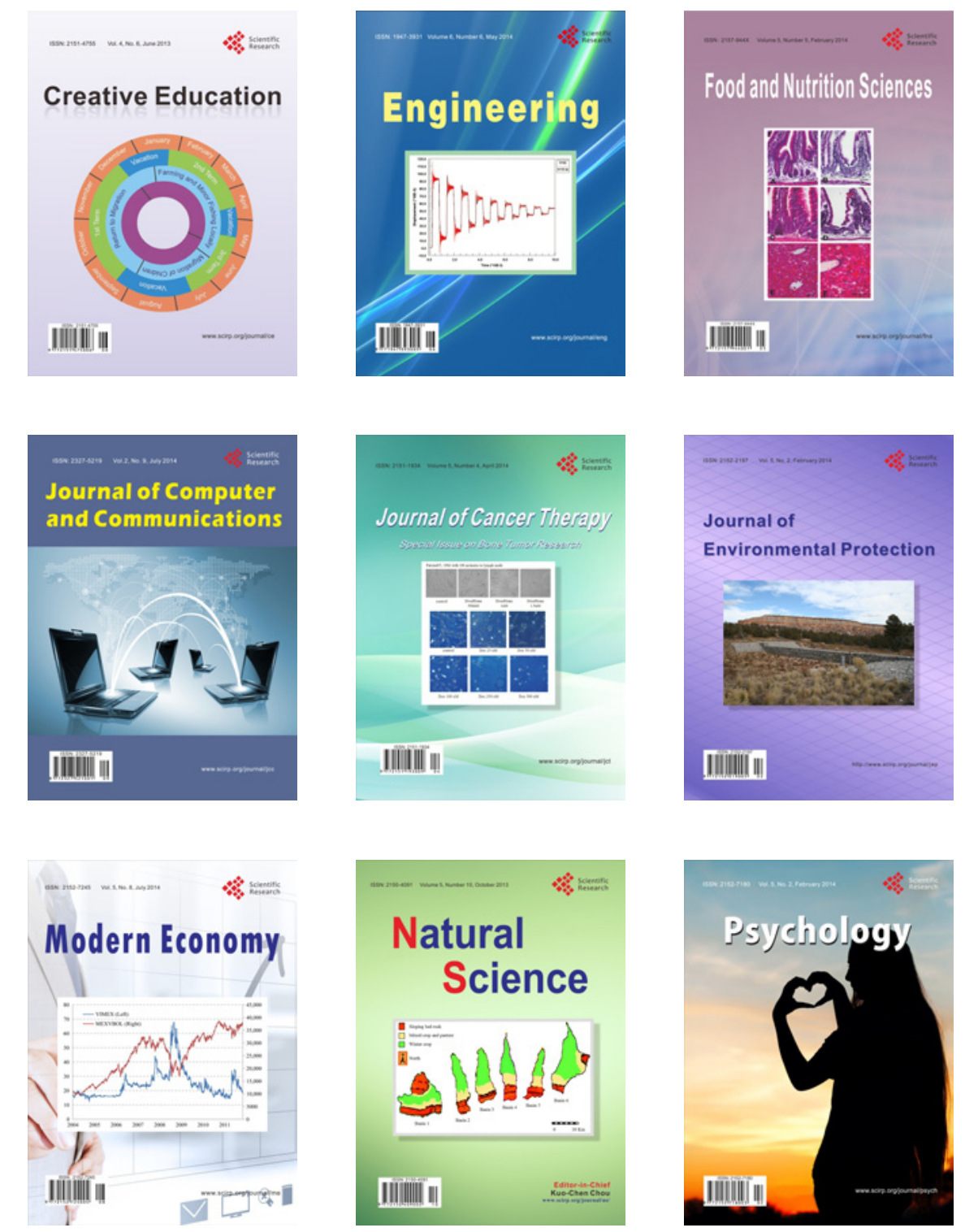